\title{
Noncontact laser sensing technology for structural health monitoring and nondestructive testing (presentation video)
}

Hoon Sohn

Hoon Sohn, "Noncontact laser sensing technology for structural health monitoring and nondestructive testing (presentation video)," Proc. SPIE 9055, Bioinspiration, Biomimetics, and Bioreplication 2014, 90550W (8 May 2014); doi: $10.1117 / 12.2049214$

Event: SPIE Smart Structures and Materials + Nondestructive Evaluation and Health Monitoring, 2014, San Diego, California, United States 


\title{
Micro-pixelation and color mixing in biological photonic structures (Presentation Video)
}

\author{
Hoon Sohn, KAIST (Republic of Korea)
}

\begin{abstract}
Noncontact sensing techniques is gaining prominence for structural health monitoring (SHM) and nondestructive testing (NDT) due to (1) their noncontact and nonintrusive natures, (2) their spatial resolution much higher than conventional discrete sensors can achieve, (3) their less dependency on baseline data obtained from the pristine condition of a target structure (reference-free diagnosis), (4) cost and labor reduction in sensor installation and maintenance. In this talk, a suite of noncontact sensing techniques particularly based on laser technology will be presented for SHM and NDT of aircraft, wind turbine blades, high-speed trains, nuclear power plants, bridges, automobile manufacturing facilities and semiconductors.
\end{abstract}

View presentation video on SPIE's Digital Library:

http://dx.doi.org/10.1117/12.2049214.3374075160001 